\title{
Role of serum periostin in severe obstructive sleep apnea with albuminuria: an observational study
}

Hironobu Sunadome ${ }^{1}$ D , Hisako Matsumoto ${ }^{* *}$, Ryo Tachikawa ${ }^{1,2}$, Takeshi Matsumoto ${ }^{1,2}$, Kiminobu Tanizawa ${ }^{1,2}$, Toru Oga ${ }^{2}$, Junya Ono ${ }^{3}$, Shoichiro Ohta ${ }^{4}$, Kenji Izuhara ${ }^{5}$, Toyohiro Hirai ${ }^{1}$ and Kazuo Chin ${ }^{2}$

\begin{abstract}
Background: Periostin is a matricellular protein and is a useful marker in respiratory diseases. However, the roles of periostin in patients with obstructive sleep apnea (OSA) remain unclear. Several in vitro studies have suggested that mechanical stress, hypoxia, impaired metabolism, and kidney injury, which often accompany OSA, may upregulate the expression of periostin. Meanwhile, serum periostin level has been negatively associated with body mass index (BMI) in the general population. In this study, we hypothesized that a high level of serum periostin despite being overweight/ obese may discriminate severe OSA or OSA with comorbidities from mild OSA with obesity alone. We aimed to clarify the roles of periostin in patients with OSA to assist in elucidating the heterogeneity of OSA with comorbidities.
\end{abstract}

Methods: Among patients diagnosed as OSA, we examined the associations between serum periostin levels and clinical indices, including the severity of OSA, BMI, and comorbidities, using a multifaceted approach. The serum periostin levels and clinical indices were assessed after 3 months of continuous positive airway pressure (CPAP) treatment.

Results: In 96 patients with OSA, serum periostin level was negatively correlated with BMI, albeit marginally, and tended to be higher in severe OSA than in others when adjusted for BMI. Cluster analysis identified four clusters, including two severe OSA clusters, one of which was characterized by high serum periostin levels and the presence of comorbidities, including albuminuria. In a comparative analysis of severe OSA cases $(n=53)$, the level of serum-free fatty acids and the frequency of albuminuria were higher in patients with high serum periostin level of $\geq 87 \mathrm{ng} / \mathrm{mL}$, which was the highest quintile among all participants, than in those with low serum periostin levels $(<87 \mathrm{ng} / \mathrm{mL}, n=41)$. In patients with severe OSA and high serum periostin levels, the levels of serum periostin and urinary albumin significantly decreased after 3 months of CPAP treatment.

Conclusions: Elevated serum periostin in patients with OSA despite being overweight/obese may be an indicator of severe OSA with comorbidities, particularly albuminuria.

Keywords: Obstructive sleep apnea, Body mass index, Serum periostin, Albuminuria

\footnotetext{
* Correspondence: hmatsumo@kuhp.kyoto-u.ac.jp

'Department of Respiratory Medicine, Graduate School of Medicine, Kyoto University, 54 Kawaharacho, Shogoin, Sakyo-ku, Kyoto city, Kyoto prefecture 606-8507, Japan

Full list of author information is available at the end of the article
}

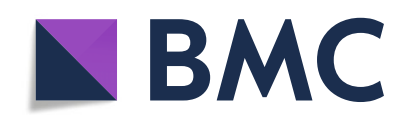

(- The Author(s). 2020 Open Access This article is licensed under a Creative Commons Attribution 4.0 International License, which permits use, sharing, adaptation, distribution and reproduction in any medium or format, as long as you give appropriate credit to the original author(s) and the source, provide a link to the Creative Commons licence, and indicate if changes were made. The images or other third party material in this article are included in the article's Creative Commons licence, unless indicated otherwise in a credit line to the material. If material is not included in the article's Creative Commons licence and your intended use is not permitted by statutory regulation or exceeds the permitted use, you will need to obtain permission directly from the copyright holder. To view a copy of this licence, visit http://creativecommons.org/licenses/by/4.0/. The Creative Commons Public Domain Dedication waiver (http://creativecommons.org/publicdomain/zero/1.0/) applies to the data made available in this article, unless otherwise stated in a credit line to the data. 


\section{Background}

Obstructive sleep apnea (OSA) is a major public health concern and has been to shown to increase in prevalence with obesity, which is its most important risk factor [1]. OSA often coexists with several respiratory and nonrespiratory diseases, including chronic obstructive pulmonary disease (COPD), asthma [2-4], abnormal glycolipid metabolism, cardiovascular diseases [1], fatty liver [5], and kidney injury [6]. OSA has deleterious effects on these comorbidities by causing mechanical stress on airways, oxidative stress by intermittent hypoxia $(\mathrm{IH})$, and interrupted sleep, all of which eventually increase the risks for poor outcomes. Besides comorbidities, OSA has recently been considered a heterogeneous disease that comprises several phenotypes with different symptoms, comorbidities, and responsiveness to continuous positive airway pressure (CPAP) treatment [7-9]. Therefore, to improve the management of OSA, recognition of comorbidities and heterogeneity in OSA is required.

Serum periostin, which is an extracellular matrix protein, is a robust marker of $\mathrm{T}$ helper type 2 (Th2) inflammation, particularly in asthma [10-12]. Interestingly, several recent studies on asthma and the general population have revealed that serum periostin was negatively associated with body mass index (BMI) [12-16] and serum leptin [15]. In addition to Th2 inflammation, periostin has been shown by in vitro studies to be upregulated under several stimulations, including mechanical stress [17] and hypoxic stimulation [18], which are major features of OSA [19]. Furthermore, periostin was suggested to play crucial roles in epithelial mesenchymal transition and lung fibrosis, both of which have been correlated with hypoxia pathways $[20,21]$. In addition, as obesity develops, the macrophages in visceral adipose tissue were demonstrated to secrete periostin, possibly in response to hypoxia [22]. Other studies reported that the expression of periostin was upregulated in fatty liver tissues [23] and in the renal tissues of a kidney injury mouse model [24].

These findings suggested that the serum periostin levels in patients with OSA may reflect a combination of its downregulation by obesity and upregulation by hypoxic stimulation or metabolic comorbidities. Therefore, we hypothesized that high serum periostin levels in patients with OSA, despite being overweight/ obese, may discriminate severe OSA or OSA with comorbidities from mild OSA with obesity alone. To test this hypothesis, we aimed to clarify the associations between serum periostin levels and the sleep metrics of OSA and its comorbidities, including dyslipidemia or kidney injury, which have not been examined previously. This may assist in understanding the heterogeneity of OSA with comorbidities.

\section{Methods}

\section{Study participants}

The participants were recruited from a cohort of clinically stable patients aged between 20 and 80 years and who were diagnosed as OSA based on the findings of overnight polysomnography (PSG) at the Sleep Laboratory of Kyoto University Hospital between March 2014 and April 2015. Patients with dominant central sleep apnea, history of previous treatment for OSA, premenopausal status, hemodialysis or uncontrolled comorbidity, or ongoing systemic corticosteroid treatment were excluded, as described previously [25].

This study was approved by the ethics committee of Kyoto University and was registered in the UMIN Clinical Trials Registry (Registry ID UMIN000012639). Written informed consent was obtained from all participants.

\section{Polysomnography}

Overnight PSG was performed between 22:00 and 06:00 using standard techniques, as described previously [25]. Apnea was defined as an airflow reduction of $>90 \%$ for $>10 \mathrm{~s}$, and hypopnea was identified as an airflow reduction of $>30 \%$ for $>10 \mathrm{~s}$ accompanied by $>3 \%$ oxygen desaturation or arousal [26]. The definitions of severity of OSA, high cumulative percentage of sleep time with percutaneous oxygen saturation $<90 \%\left(\mathrm{CT}_{90}\right)$, high $(\geq 3 \%)$ oxygen desaturation index ( $3 \% \mathrm{ODI})$, and high arousal index (AI) are described in the Supplementary Methods (Additional file 1). Participants with apnea-hypopnea index (AHI) of $\geq 20$ were treated with CPAP according to the health insurance system in Japan.

\section{Assessments}

Assessments were performed on the first diagnostic PSG (baseline) and on the follow-up PSG 3 months after CPAP initiation. Patient history was taken at baseline. Physical examinations, blood tests, and urinalysis were performed at baseline and on follow-up PSG. Blood samples were collected between 06:30 and 07:00 after the completion of PSG. Sample analyses included blood glucose and serum levels of insulin, lipids, and periostin. Serum periostin levels were measured using an enzymelinked immunosorbent assay at Shino-Test Corporation (Kanagawa, Japan). Using a 12-h overnight urine sample, urinalysis and analysis of urine albumin and creatinine were performed [27]. The degree of albuminuria was determined by the urine albumin $(\mathrm{mg})$-creatinine $(\mathrm{g})$ ratio (UACR), as follows: microalbuminuria for UACR of > $20 \mathrm{mg} / \mathrm{g}$ in men and $>30 \mathrm{mg} / \mathrm{g}$ in women and macroalbuminuria for UACR of $>300 \mathrm{mg} / \mathrm{g}$ [28]. The definitions of other comorbidities, including hypertension, dyslipidemia, diabetes mellitus (DM), COPD, asthma, and allergic rhinitis, are described in the Supplementary Methods (Additional file 1). 
The associations between serum periostin levels and the severity of OSA; sleep metrics, including $\mathrm{CT}_{90}, 3 \%$ $\mathrm{ODI}$, and AI; and the other clinical indices were evaluated. Changes in the measurements from baseline to after 3 months of CPAP therapy were examined.

\section{Statistical analysis}

Statistical analyses were performed using $\mathrm{JMP}^{\oplus}$ version 12 (SAS Institute, Tokyo, Japan). Comparisons between two or more groups were performed using t-test, $x^{2}$ test, or Wilcoxon rank sum test, as appropriate. To determine correlations between continuous variables, the linear least squares method was used. For statistical analysis, the common logarithm of the serum periostin level was used. To assess the associations among serum periostin, severe OSA, and comorbidities, cluster analysis was performed. The detailed methods are described in the Supplementary Methods (Additional file 1). The interactions of serum periostin levels with sleep metrics and clinical indices were assessed. Finally, changes in the paired variables after CPAP treatment were examined using paired t-test, Wilcoxon signed-rank test, or $\mathrm{McNe}$ mar test, as appropriate. Data are presented as the mean $\pm \mathrm{SD}$, and $p \leq 0.05$ was considered to indicate statistical significance.

\section{Results}

\section{Participant characteristics}

Of 188 patients in total, 97 met the inclusion criteria but 1 withdrew from the original study and rejected the secondary use of specimens [25]. Therefore, the final analyses were conducted for 96 patients (Fig. 1). The characteristics of the patients are presented in Table 1. The mean serum periostin level was $67.3 \pm$ $22.8 \mathrm{ng} / \mathrm{mL}$, which was equivalent to the average of the general population in Japan [15]. Among 96 subjects, 86 had at least one of the major comorbidities, such as DM, hypertension, dyslipidemia, albuminuria, COPD, asthma, or allergic rhinitis.

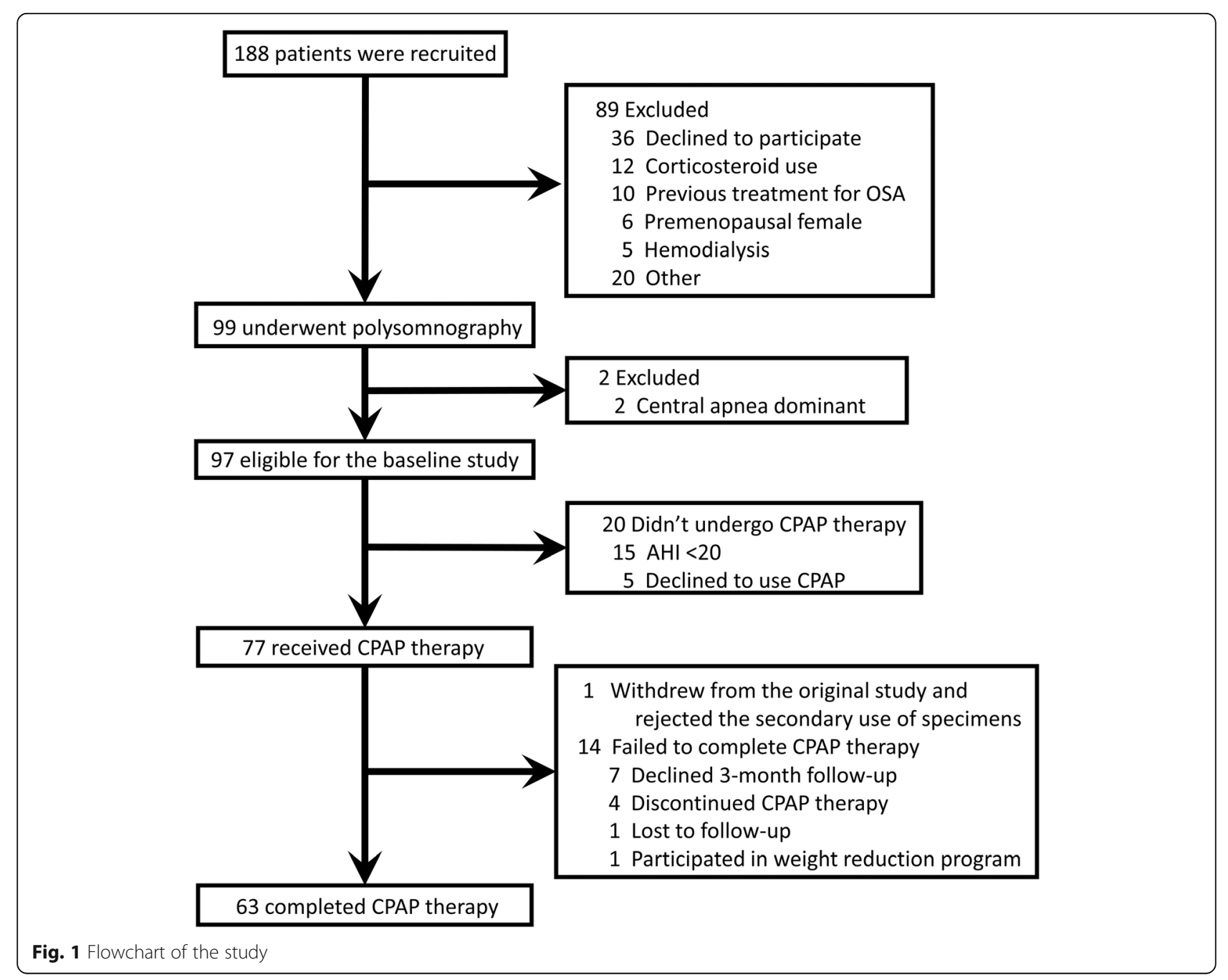


Table 1 Patient characteristics

\begin{tabular}{|c|c|}
\hline \multicolumn{2}{|l|}{ Index } \\
\hline \multicolumn{2}{|l|}{ Clinical background } \\
\hline Age, years & $56 \pm 11$ \\
\hline Sex, male/female, $n$ & $74 / 22$ \\
\hline $\mathrm{BMI}, \mathrm{kg} / \mathrm{m}^{2}$ & $27.6 \pm 4.2$ \\
\hline Abdominal circumference, $\mathrm{cm}$ & $94.8 \pm 20.7$ \\
\hline Smoking, current/others, $\mathrm{n}$ & $21 / 75$ \\
\hline \multicolumn{2}{|l|}{ Sleep parameters } \\
\hline AHI, events/h & $36.5 \pm 20.7$ \\
\hline $\mathrm{CT}_{90} \%$ & $13.1 \pm 18$ \\
\hline Lowest oxygen saturation, \% & $78.9 \pm 8.3$ \\
\hline $3 \%$ ODI, events/h & $35.3 \pm 20.5$ \\
\hline Arousal index, events/h & $34.4 \pm 17.8$ \\
\hline OSA, mild/moderate/severe ${ }^{a}, \mathrm{n}$ & $12 / 31 / 53$ \\
\hline \multicolumn{2}{|l|}{ Comorbidities } \\
\hline Diabetes mellitus, $+/-, \mathrm{n}$ & $26 / 70$ \\
\hline Insulin use, $+/-$, n & $5 / 91$ \\
\hline Hypertension, +/-, n & $58 / 38$ \\
\hline Hypertension (self-reported), $+/-, \mathrm{n}$ & $65 / 31$ \\
\hline Dyslipidemia, +/-, n & $62 / 34$ \\
\hline Albuminuria ${ }^{\mathrm{b}}$, macro/micro/-, n & $2 / 12 / 82$ \\
\hline Chronic obstructive pulmonary disease, $+/-, \mathrm{n}$ & $2 / 94$ \\
\hline Asthma, $+/-, \mathrm{n}$ & $4 / 92$ \\
\hline Allergic rhinitis, $+/-, \mathrm{n}$ & $16 / 80$ \\
\hline \multicolumn{2}{|l|}{ Blood/Urine tests } \\
\hline Total cholesterol, mg/dL & $196 \pm 34$ \\
\hline High-density lipoprotein, mg/dL & $53 \pm 15$ \\
\hline Low-density lipoprotein, mg/dL & $117 \pm 30$ \\
\hline Triglycerides, mg/dL & $172 \pm 121$ \\
\hline Free fatty acids, mg/dL & $490 \pm 160$ \\
\hline Blood glucose, mg/dL & $101 \pm 24$ \\
\hline Hemoglobin A1c, \% & $6.2 \pm 0.9$ \\
\hline Insulin, $\mu \mathrm{U} / \mathrm{mL}$ & $10.7 \pm 10.2$ \\
\hline Serum periostin, ng/mL & $67.3 \pm 22.8$ \\
\hline Urinary albumin-creatinine ratio ${ }^{c}, \mathrm{mg} / \mathrm{g}$ & $25.4 \pm 107.1$ \\
\hline
\end{tabular}

Baseline data are presented as mean \pm SD or number

aseverity of OSA was defined on the basis of the AHI, as follows: mild, $\geq 5$ to $<15$;

moderate, $\geq 15$ to $<30$; or severe, $\mathrm{AHI} \geq 30$

${ }^{b}$ Defined as positive if the urinary albumin-creatinine ratio was $\geq 20 \mathrm{mg} / \mathrm{g}$ in men or $\geq 30 \mathrm{mg} / \mathrm{g}$ in women. 'Defined as urine albumin/creatinine $B M I$ body mass index, $A H I$ apnea-hypopnea index, $C T_{90}$ cumulative percentage of sleep time with percutaneous oxygen saturation $<90 \%$, ODI oxygen desaturation index
Associations between serum periostin level and clinical variables in OSA: BMI, disease severity, sleep metrics, and other clinical indices

The associations between the serum periostin level and the clinical indices are presented in Table 2. Serum periostin level was positively correlated with age $(p<0.05)$ but was negatively correlated with BMI, albeit marginally ( $p=0.055$, Fig. 2$)$. The serum periostin level did not differ between patients with severe OSA $(n=53)$ and those with mild to moderate OSA $(n=43) \quad(p=0.28)$, but it tended to be higher in patients with severe OSA when adjusted by BMI $(p=0.07)$ (Fig. 3a). Furthermore, serum periostin level was significantly higher in patients with high ODI ( $3 \%$ ODI $\geq 30.2 / \mathrm{h}$ ) than in those with low ODI without adjustment $(p=0.03$, Fig. 3b). The $\mathrm{CT}_{90}$, lowest oxygen saturation, and AI were not associated with serum periostin level, even after adjustment for BMI (data not shown). In addition, serum periostin level was not associated with the presence of major comorbidities, including COPD $(p=0.13)$, asthma $(p=0.32)$, and allergic rhinitis $(p=0.93)$ (Figure $\mathrm{S} 1$ in Additional file 1).

\section{Cluster analysis and comparative analysis in patients with severe OSA}

Subsequently, to comprehensively understand the associations among serum periostin levels, severe OSA, and comorbidities, cluster analysis was performed. This identified four clusters (Table 3 and Figure S2 and Supplementary Results in Additional file 1), including two clusters characterized by severe OSA (clusters 3 and 4). Compared with cluster 3, cluster 4 showed a high serum periostin level $(87.1 \pm 32.3$ vs. $66.5 \pm 21.8 \mathrm{ng} / \mathrm{mL}, p=0.05)$ and a higher prevalence of the comorbidities: DM $(p<0.01)$, albuminuria $(p<$ $0.01)$, hypertension $(p=0.03)$, and asthma $(p=0.01)$.

The patients with severe OSA were divided into two groups, using a cutoff serum periostin level of $87 \mathrm{ng} / \mathrm{mL}$, which was equivalent to the highest quintile of serum periostin among all participants. Compared with the severe OSA alone group $(n=41)$, the severe OSA with high periostin group $(n=12)$ exhibited significantly higher free fatty acid levels $(p=$ $0.03)$ and prevalence of albuminuria $(p=0.04)$ (Table $4)$ and a trend for more frequent DM $(p=0.07)$ and asthma $(p=0.06)$.

Finally, among the entire study population, patients with severe OSA or high 3\% ODI exhibited positive interactions with albuminuria for serum periostin levels $(p<0.01$, Fig. 4a and b). No such interaction for high serum periostin level was observed in the associations between severe OSA and serum-free fatty acid or blood glucose (data not shown). 
Table 2 Univariate linear regression analysis of the associations between clinical indices and serum periostin level ${ }^{\mathrm{a}}$

\begin{tabular}{|c|c|c|}
\hline Index & Estimate for serum periostin ${ }^{a}(95 \% \mathrm{Cl})$ & $\boldsymbol{p}$-value \\
\hline Age, years & $3.9 \times 10^{-3}\left(1.3 \times \times 10^{-3}-6.6 \times 10^{-3}\right)$ & $<0.01$ \\
\hline $\mathrm{BMI}, \mathrm{kg} / \mathrm{m}^{2}$ & $-6.9 \times 10^{-3}\left(-14 \times 10^{-3}-0.2 \times 10^{-3}\right)$ & 0.055 \\
\hline $\mathrm{AHI}$, event/h & $0.2 \times 10^{-3}\left(-1.3 \times 10^{-3}-1.6 \times 10^{-3}\right)$ & 0.82 \\
\hline $\mathrm{CT}_{90} \%$ & $-0.2 \times 10^{-3}\left(-1.9 \times 10^{-3}-1.4 \times 10^{-3}\right)$ & 0.73 \\
\hline Lowest oxygen saturation, \% & $2 \times 10^{-4}\left(-3.4 \times 10^{-3}-3.8 \times 10^{3}\right)$ & 0.91 \\
\hline $3 \%$ ODI, event/h & $6.5 \times 10^{-5}\left(-1.4 \times 10^{-3}-1.5 \times 10^{-3}\right)$ & 0.92 \\
\hline Arousal index, event/h & $3.8 \times 10^{-4}\left(-1.3 \times 10^{-3}-0.002\right)$ & 0.66 \\
\hline Total cholesterol, mg/dL & $-0.6 \times 10^{-3}\left(-1.5 \times 10^{-3}-0.3 \times 10^{-3}\right)$ & 0.19 \\
\hline High-density lipoprotein, mg/dL & $0.6 \times 10^{-3}\left(-1.4 \times 10^{-3}-2.7 \times 10^{-3}\right)$ & 0.53 \\
\hline Low-density lipoprotein, mg/dL & $-0.3 \times 10^{-3}\left(-1.3 \times 10^{-3}-0.6 \times 10^{-3}\right)$ & 0.49 \\
\hline Triglycerides, mg/dL & $-0.2 \times 10^{-3}\left(-0.4 \times 10^{-3}-0.09 \times 10^{-3}\right)$ & 0.22 \\
\hline Free fatty acids, mg/dL & $0.09 \times 10^{-3}\left(-0.1 \times 10^{-3}-0.3 \times 10^{-3}\right)$ & 0.37 \\
\hline Blood glucose, mg/dL & $1.6 \times 10^{-3}\left(0.4 \times 10^{-3}-2.8 \times 10^{-3}\right)$ & $<0.01$ \\
\hline Hemoglobin A1c, \% & $35.3 \times 10^{-3}\left(1.8 \times 10^{-3}-68.8 \times 10^{-3}\right)$ & 0.04 \\
\hline Urinary albumin-creatinine ratio ${ }^{b}, \mathrm{mg} / \mathrm{g}$ & $1.61 \times 10^{-5}\left(-26.3 \times 10^{-5}-29.6 \times 10^{-5}\right)$ & 0.91 \\
\hline
\end{tabular}

Log-transformed. ${ }^{\mathrm{b}}$ Defined as urine albumin/creatinine

$\mathrm{Cl}$ confidence interval, $B M I$ body mass index, $A H I$ apnea-hypopnea index, $C T_{90}$ cumulative percentage of sleep time with percutaneous oxygen saturation $<90 \%$, $O D I$ oxygen desaturation index

\section{Responsiveness to CPAP treatment in patients with severe OSA}

Treatment with CPAP was completed successfully in 8 patients from the severe OSA with high periostin group and in 35 patients from the severe OSA alone group. In both groups, marked improvements in sleep metrics were observed (Table 5) and UACR decreased significantly after CPAP treatment, although this decrease was more marked in the severe OSA with high periostin group than that in the severe OSA alone group $(-71.4 \pm 186.2 \mathrm{mg} / \mathrm{g}$ vs. $12.9 \pm 63.1 \mathrm{mg} / \mathrm{g}, \quad p=0.04)$. Significant decrease in the serum periostin level after CPAP treatment was seen in the severe OSA with high periostin group $(p=0.04)$ but not in the severe OSA alone group $(p=0.38)$. The serum periostin level did not decrease in subjects with moderate OSA ( $p=0.75$, Table S1 in Additional file 1).

\section{Discussion}

To the best of our knowledge, this is the first study to demonstrate that serum periostin plays a role in severe OSA. Severe OSA, which is defined as AHI $>30$, alone was not associated with serum periostin levels; this result may have been affected by the negative influence of BMI on serum periostin level. However, a high 3\% ODI

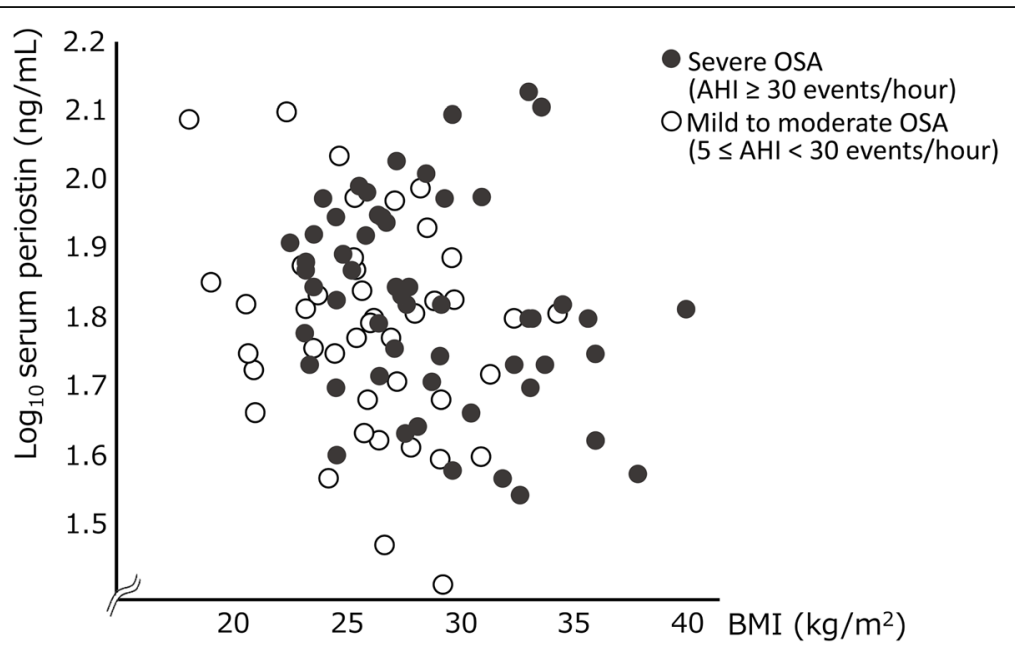

Fig. 2 Associations between BMI and serum periostin at baseline. Black circles represent patients with severe OSA (AHI $\geq 30$ ), and white circles represent patients with mild to moderate OSA (AHI $\geq 5$ to < 30). BMI, body mass index; OSA, obstructive sleep apnea; AHI, apnea-hypopnea index 

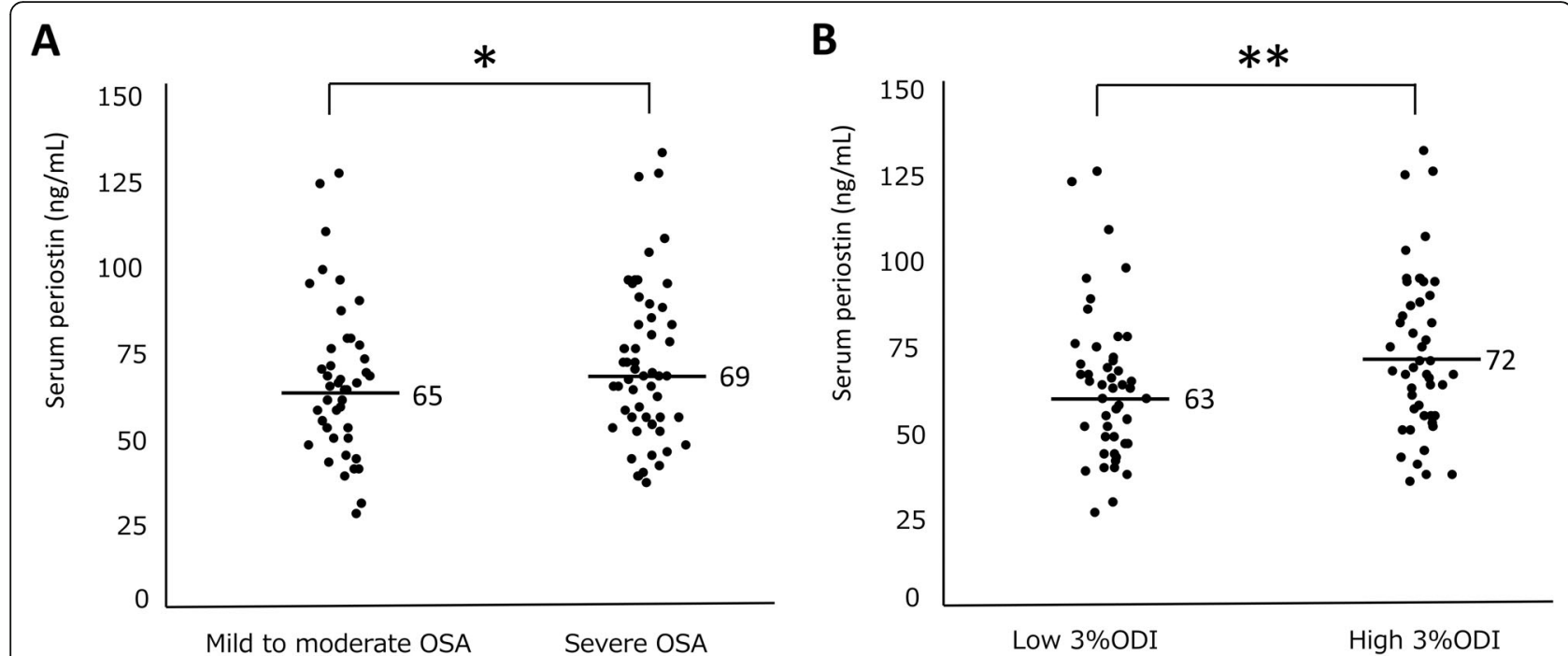

Fig. 3 Associations between sleep metrics and serum periostin at baseline. a Severity of OSA and serum periostin $\left(^{*} p=0.28\right.$ without adjustment for BMI, $p=0.07$ with adjustment for BMI and $\mathbf{b} 3 \% \mathrm{ODI}$ and serum periostin (** $p=0.03$ without adjustment for BMI). High ODI was defined as $3 \%$ $\mathrm{ODI} \geq 30.2 / \mathrm{h}$, which was equivalent to the top $50 \%$ of the participants. OSA, obstructive sleep apnea; BMI, body mass index; $3 \%$ ODI, oxygen desaturation $(\geq 3 \%)$ index

was significantly associated with serum periostin level. Notably, in the cluster and comparative analyses, an elevated serum periostin level was associated with albuminuria among patients who had severe OSA or high 3\% ODI. These findings indicated that overweight/obese patients with elevated serum periostin level may comprise a specific subtype of severe OSA with albuminuria (Figure S3 in Additional file 1) and require careful follow-up.

Recently, heterogeneity has been recognized in OSA, particularly in severe OSA [29]. Previous studies that used cluster analysis demonstrated several severe OSA phenotypes, which exhibited similar AHI-based severity but different symptoms or frequencies of comorbidities $[7,8]$. The present study identified four clusters that differed in age, sleep metrics, and laboratory data. Of the two distinct clusters of severe OSA, the cluster with comorbidities showed a trend of higher 3\% ODI, compared with that in the cluster without comorbidities. This result was consistent with the previous findings that $\mathrm{IH}$, which is represented by ODI, played a significant role in systemic inflammation [30] and was, in itself, a likely risk factor for comorbidities [31].

Periostin is secreted as a 93.3-kDa extracellular matrix protein [11]. Consistent with previous studies on patients with asthma and the general population [12-16], the present study showed that the serum periostin level was negatively associated with BMI, albeit marginally. This precluded us from using serum periostin as a simple marker to predict severe OSA. Therefore, we examined a severe OSA phenotype that was associated with high serum periostin, based on our findings in the cluster analysis and on previous experimental studies, which showed that the major pathologic features of OSA were associated with the upregulation of periostin. In particular, IH stimulation, as represented by the ODI, was shown to induce oxidative stress, production of reactive oxidative species, and activation of nuclear factor $-\kappa B$ pathways, which may result in the upregulation of periostin [32-34]. In the present study, high 3\% ODI was significantly associated with the serum periostin level (Fig. 3b). Importantly, patients with severe OSA and elevated serum periostin level showed a decrease in serum periostin after CPAP treatment.

In the present study, significant associations among albuminuria, severe OSA, and high serum periostin level were observed consistently in both the cluster and comparative analyses. In some studies, periostin was shown to be upregulated in the renal tissues and in the urine of patients with diabetic nephropathy [24], as well as in mouse models of kidney injury [35]. However, no studies have shown elevation of serum periostin levels in patients with albuminuria. In addition, epidemiologic studies on the association of serum periostin levels with renal function have yielded inconsistent results $[15,36]$. Meanwhile, albuminuria is one of the important comorbidities associated with OSA [27, 37], probably as a result of sleep-related pathophysiologic changes in the glomerulus [27]. In a mouse model of OSA, IH was shown to cause kidney injury accompanied by increased urinary albumin levels, possibly through glomerular hypertrophy, and increased expression of transforming growth factor- $\beta 1$ and connective tissue growth factor [38]. On the basis of the fact that these are well-known upregulators of periostin expression [39], our present 
Table 3 Characteristics of each cluster

\begin{tabular}{|c|c|c|c|c|c|c|}
\hline \multirow[t]{2}{*}{ Index } & \multicolumn{4}{|l|}{ Cluster (n) } & \multicolumn{2}{|l|}{$\boldsymbol{p}$-value } \\
\hline & $1(6)$ & $2(30)$ & $3(52)$ & $4(8)$ & All cluster & 3 vs. 4 \\
\hline Age, years & $47 \pm 9$ & $63 \pm 9$ & $59 \pm 12$ & $63 \pm 8$ & 0.01 & 0.33 \\
\hline Sex, male/female, $n$ & $6 / 0$ & $23 / 7$ & $40 / 12$ & $5 / 3$ & 0.43 & 0.38 \\
\hline Smoking, current/others, n & $3 / 3$ & $9 / 21$ & $7 / 45$ & $2 / 6$ & 0.11 & 0.39 \\
\hline $\mathrm{BMl}, \mathrm{kg} / \mathrm{m}^{2}$ & $29.6 \pm 2$ & $27.1 \pm 3.1$ & $27.4 \pm 4.6$ & $30 \pm 5.2$ & 0.26 & 0.24 \\
\hline $\mathrm{AHI}$, events/h & $33 \pm 33$ & $29 \pm 17$ & $39 \pm 20$ & $51 \pm 18$ & $<0.01$ & 0.08 \\
\hline Severity of OSA ${ }^{a}$, mild-moderate/severe, $n$ & $5 / 1$ & $22 / 8$ & $15 / 37$ & $1 / 7$ & $<0.01$ & 0.33 \\
\hline $\mathrm{CT}_{90} \%$ & $12.7 \pm 25.3$ & $13.3 \pm 19.1$ & $12.3 \pm 16.4$ & $18.5 \pm 21.1$ & 0.85 & 0.22 \\
\hline Lowest oxygen saturation, \% & $76.5 \pm 12.5$ & $80.5 \pm 7.3$ & $79.2 \pm 8.0$ & $73.3 \pm 9.5$ & 0.14 & 0.1 \\
\hline $3 \%$ ODI, events/h & $31.2 \pm 33.8$ & $28.2 \pm 17.3$ & $35.6 \pm 19.6$ & $50.6 \pm 19.7$ & 0.04 & 0.06 \\
\hline High ODI,$+/-, n$ & $1 / 5$ & $9 / 21$ & $31 / 21$ & $7 / 1$ & $<0.01$ & 0.13 \\
\hline Arousal index, events/h & $21.5 \pm 10.9$ & $29.4 \pm 13.9$ & $40.6 \pm 19.4$ & $37.8 \pm 19.1$ & 0.03 & 0.66 \\
\hline Serum periostin, ng/mL & $48.2 \pm 14.7$ & $67.1 \pm 19.7$ & $66.5 \pm 21.8$ & $87.1 \pm 32.3$ & 0.04 & 0.05 \\
\hline Serum periostin, high/low ${ }^{c}, \mathrm{n}$ & $0 / 6$ & $7 / 23$ & $8 / 44$ & $4 / 4$ & 0.07 & 0.02 \\
\hline Blood eosinophils, $/ \mu \mathrm{L}$ & $204(99-334)$ & $202(159-355)$ & $225(124-317)$ & $245(165-288)$ & 0.86 & 0.68 \\
\hline Total cholesterol, mg/dL & $228 \pm 39$ & $186 \pm 32$ & $195 \pm 31$ & $215 \pm 41$ & 0.03 & 0.11 \\
\hline High-density lipoprotein, mg/dL & $44 \pm 10$ & $52 \pm 13$ & $55 \pm 16$ & $53 \pm 14$ & 0.27 & 0.69 \\
\hline Low-density lipoprotein, mg/dL & $155 \pm 33$ & $107 \pm 34$ & $117 \pm 25$ & $126 \pm 20$ & $<0.01$ & 0.36 \\
\hline Triglycerides, mg/dL & $190 \pm 74$ & $177 \pm 75$ & $152 \pm 110$ & $263 \pm 266$ & 0.05 & 0.04 \\
\hline Free fatty acids, mg/dL & $409 \pm 103$ & $535 \pm 177$ & $460 \pm 147$ & $577 \pm 151$ & 0.03 & 0.04 \\
\hline Blood glucose, mg/dL & $96 \pm 14$ & $112 \pm 26$ & $92 \pm 11$ & $130 \pm 45$ & $<0.01$ & $<0.01$ \\
\hline Hemoglobin A1c, \% & $5.8 \pm 0.4$ & $6.8 \pm 1.0$ & $5.8 \pm 0.4$ & $7.2 \pm 1.1$ & $<0.01$ & $<0.01$ \\
\hline Dyslipidemia, +/-, n & $5 / 1$ & $26 / 4$ & $26 / 26$ & $5 / 3$ & $<0.01$ & 0.16 \\
\hline Diabetes mellitus, $+/-, \mathrm{n}$ & $0 / 6$ & $21 / 9$ & $0 / 52$ & $5 / 3$ & $<0.01$ & $<0.01$ \\
\hline Hypertension, +/-, n & $2 / 4$ & $25 / 5$ & $24 / 28$ & $7 / 1$ & $<0.01$ & 0.03 \\
\hline Urinary albumin-creatinine ratio ${ }^{d}, \mathrm{mg} / \mathrm{g}$ & $30.5 \pm 5.5$ & $6.4 \pm 3.7$ & $4.7 \pm 2.7$ & $228.3 \pm 322.3$ & $<0.01$ & $<0.01$ \\
\hline Albuminuriae ${ }^{e}$ macro/micro/-, n & 0/6/0 & $0 / 0 / 30$ & $0 / 0 / 52$ & $2 / 6 / 0$ & $<0.01$ & $<0.01$ \\
\hline History of coronary artery disease, $+/-, \mathrm{n}$ & $0 / 6$ & $2 / 28$ & $4 / 48$ & $0 / 8$ & 0.77 & 0.42 \\
\hline History of stroke, $+/-$, n & $1 / 5$ & $0 / 30$ & $3 / 49$ & $1 / 7$ & 0.25 & 0.48 \\
\hline Chronic obstructive pulmonary disease, $+/-, \mathrm{n}$ & $0 / 6$ & $1 / 29$ & $1 / 51$ & $0 / 8$ & 0.91 & 0.69 \\
\hline Asthma, +/-, n & $1 / 5$ & $0 / 30$ & $1 / 51$ & $2 / 6$ & $<0.01$ & 0.01 \\
\hline Allergic rhinitis, $+/-, \mathrm{n}$ & $0 / 6$ & $4 / 26$ & $11 / 41$ & $1 / 7$ & 0.51 & 0.57 \\
\hline
\end{tabular}

Baseline data are presented as mean \pm SD or numbers, except for eosinophils, which are presented as median (range)

${ }^{a}$ Severity of OSA was defined on the basis of the AHI, as follows: mild, $\geq 5$ to $<15$; moderate, $\geq 15$ to $<30$; or severe, AHI $\geq 30$. ${ }^{b}$ Defined as $3 \%$ ODI $\geq 30.2 / h$, which was equivalent to the top $50 \%$ of all participants. ${ }^{\mathrm{C} D e f i n e d}$ as serum periostin $\geq 87 \mathrm{ng} / \mathrm{mL}$, the highest quintile. ${ }^{\mathrm{d} D e f i n e d}$ as urine albumin/creatinine. ${ }^{\mathrm{e}} \mathrm{A}$ urinary albumin-creatinine ratio of $\geq 300 \mathrm{mg} / \mathrm{g}$ in men and women was considered as macroalbuminuria, and a value of $\geq 20 \mathrm{mg} / \mathrm{g}$ in men or $\geq 30 \mathrm{mg} / \mathrm{g}$ in women was considered as microalbuminuria

$B M I$ body mass index, $A H I$ apnea-hypopnea index, $C T_{90}$ cumulative percentage of sleep time with percutaneous oxygen saturation $<90 \%, O D I$ oxygen desaturation index

findings of high serum periostin levels in patients with severe OSA and albuminuria may reflect the synergistic effect of kidney injury and repetitive $\mathrm{IH}$ stimulation. Although serum periostin level was not associated with albuminuria alone, it had a positive interaction with albuminuria and severe OSA or high 3\% ODI (Fig. 4). In conclusion, from a clinical standpoint, having high serum periostin levels despite being overweight/obese may be an identifier of a severe OSA with albuminuria subtype, which may benefit from CPAP treatment, as observed in this study.

The present study had several limitations. First, besides its retrospective nature, this study did not discuss certain severe comorbidities of OSA, such as arrhythmia and heart failure. This was due to an insufficient number of subjects with these comorbidities. Similarly, this study 
Table 4 Characteristics of patients with severe OSA and high serum periostin

\begin{tabular}{|c|c|c|c|c|}
\hline Index & $\begin{array}{l}\text { Mild } / \text { moderate OSA } \mathrm{n}= \\
43\end{array}$ & $\begin{array}{l}\text { Severe OSA alone } n= \\
41 \\
n=41\end{array}$ & $\begin{array}{l}\text { Severe OSA } A^{a}+\text { high periostin }^{b} n= \\
12\end{array}$ & $\begin{array}{l}\boldsymbol{p}^{-} \\
\text {value }^{\ddagger}\end{array}$ \\
\hline Age, years & $60 \pm 10$ & $58 \pm 12$ & $63 \pm 9$ & 0.16 \\
\hline Sex, male/female, n & $33 / 10$ & $31 / 10$ & $10 / 2$ & 0.57 \\
\hline Smoking, current/others, n & $12 / 31$ & $8 / 33$ & $1 / 11$ & 0.36 \\
\hline $\mathrm{BMl}, \mathrm{kg} / \mathrm{m}^{2}$ & $26.2 \pm 3.5$ & $28.9 \pm 4.6$ & $28.6 \pm 3$ & 0.83 \\
\hline AHl, events/h & $18.8 \pm 6.9$ & $51.1 \pm 17.5$ & $50 \pm 13.5$ & 0.90 \\
\hline $\mathrm{CT}_{90}, \%$ & $5.5 \pm 8.0$ & $21 \pm 22.7$ & $13.8 \pm 14.8$ & 0.59 \\
\hline $3 \%$ ODI, events/h & $17.5 \pm 7.3$ & $48.5 \pm 18.6$ & $46.1 \pm 13.4$ & 0.83 \\
\hline Lowest oxygen saturation, \% & $82.6 \pm 7.6$ & $76 \pm 7.5$ & $75.6 \pm 8.4$ & 0.98 \\
\hline Arousal index, events/h & $21.8 \pm 8.8$ & $45.4 \pm 17.8$ & $41.8 \pm 12.6$ & 0.51 \\
\hline Serum periostin, ng/mL & $64.7 \pm 22.4$ & $59.7 \pm 13.9$ & $102.7 \pm 15.4$ & - \\
\hline Blood eosinophils, $/ \mu \mathrm{L}$ & $202(124-350)$ & $219(131-299)$ & $240(155-284)$ & 0.92 \\
\hline Total cholesterol, mg/dL & $195 \pm 32$ & $199 \pm 37$ & $189 \pm 32$ & 0.40 \\
\hline High-density lipoprotein, mg/dL & $55 \pm 16$ & $53 \pm 13$ & $48 \pm 15$ & 0.30 \\
\hline Low-density lipoprotein, mg/dL & $114 \pm 34$ & $121 \pm 28$ & $111 \pm 21$ & 0.22 \\
\hline Triglycerides, mg/dL & $158 \pm 90$ & $175 \pm 148$ & $207 \pm 117$ & 0.49 \\
\hline Free fatty acids, mg/dL & $480 \pm 172$ & $474 \pm 147$ & $581 \pm 139$ & 0.03 \\
\hline Blood glucose, mg/dL & $100 \pm 23$ & $100 \pm 23$ & $113 \pm 33$ & 0.12 \\
\hline Hemoglobin A1c, \% & $6.2 \pm 0.9$ & $6.1 \pm 0.8$ & $6.5 \pm 1.1$ & 0.19 \\
\hline Dyslipidemia, +/-, n & $15 / 28$ & $16 / 25$ & $7 / 5$ & 0.24 \\
\hline Diabetes mellitus, $+/-, \mathrm{n}$ & $14 / 29$ & $7 / 34$ & $5 / 7$ & 0.07 \\
\hline Hypertension, $+/-$, n & $22 / 21$ & $29 / 12$ & $8 / 4$ & 0.79 \\
\hline Urinary albumin-creatinine ratio ${ }^{c}, \mathrm{mg} / \mathrm{g}$ & $10.5 \pm 15.9$ & $22.5 \pm 89.4$ & $89.4 \pm 258.5$ & 0.31 \\
\hline Albuminuria ${ }^{d}$, macro/micro/-, n & $0 / 6 / 37$ & $1 / 3 / 37$ & $1 / 3 / 8$ & $0.04^{\mathrm{e}}$ \\
\hline $\begin{array}{l}\text { Chronic obstructive pulmonary disease, }+/- \text {, } \\
\text { n }\end{array}$ & $1 / 41$ & $0 / 41$ & $1 / 11$ & 0.06 \\
\hline Asthma, $+/-, \mathrm{n}$ & $1 / 42$ & $1 / 40$ & $2 / 10$ & 0.06 \\
\hline Allergic rhinitis, $+/-, \mathrm{n}$ & $8 / 35$ & $6 / 35$ & $2 / 10$ & 0.89 \\
\hline
\end{tabular}

Baseline data are presented as mean \pm SD or numbers, except for eosinophils, which were presented as median (range)

a Severity of OSA was defined on the basis of the AHI, as follows: mild, $\geq 5$ to $<15$; moderate, $\geq 15$ to $<30$; or severe, AHI $\geq 30$

${ }^{b}$ Determined as high when the serum periostin level was $\geq 87 \mathrm{ng} / \mathrm{mL}$ (highest quintile)

${ }^{\ddagger} p$-values for severe OSA + high serum periostin vs. severe OSA alone

'Defined as urine albumin/creatininec

${ }^{\mathrm{d}}$ Defined as positive if the urinary albumin-creatinine ratio was $\geq 20 \mathrm{mg} / \mathrm{g}$ in $\mathrm{men}$ or $\geq 30 \mathrm{mg} / \mathrm{g}$ in women

${ }^{\text {e}}$ Compared frequency of albuminuria

OSA obstructive sleep apnea, $B M I$ body mass index, $A H I$ apnea-hypopnea index, $C T_{90}$ cumulative percentage of sleep time with percutaneous oxygen saturation < $90 \%, O D I$ oxygen desaturation index

included few subjects with COPD, which is an important confounder of the severity of OSA and hypoxia [27]. However, even after excluding subjects with COPD, we confirmed that severe OSA was associated with high serum periostin level after adjustment for BMI and that high serum periostin level in severe OSA was a risk factor for albuminuria ( $p=0.03$, data not shown). Second, the presence of hypertension or dyslipidemia was defined according to the intake of antihypertensive or lipid-lowering medications. However, even if based on the diagnosis on self-reported disease (Table 1), we found that the prevalence of hypertension was similar in both the cluster and comparative analyses (data not shown). Third, the study included subjects who had already been treated with medications that may influence urinary albumin or lipid metabolism. This was inevitable, because many patients with OSA have these comorbidities that require medications [27]. Finally, four patients had comorbid asthma, and they exhibited numerically higher serum periostin level, compared with that in the remaining subjects (Figure S1 in Additional file 1). Even after excluding asthmatics from the analysis, the presence of albuminuria was seen in the severe OSA with high periostin group than in the severe OSA alone group $(p=0.03)$. Furthermore, the findings of 


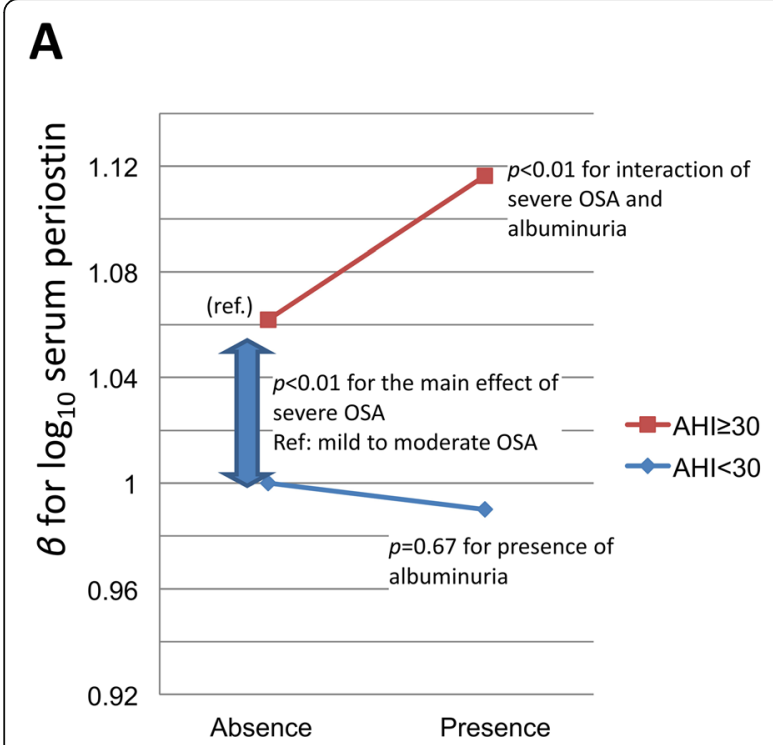

Albuminuria

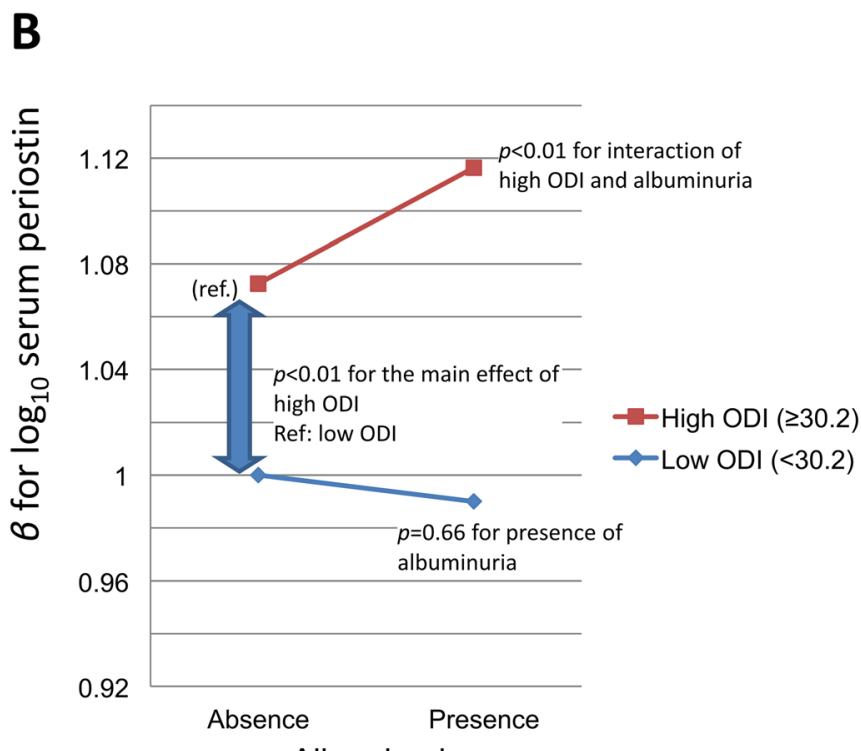

Albuminuria

Fig. 4 Positive interaction for serum periostin levels between severe OSA or high 3\% ODI and albuminuria. a Severe OSA and presence of albuminuria and $\mathbf{b}$ high $3 \% \mathrm{ODI}$ and presence of albuminuria. Albuminuria was considered present if the urinary albumin-creatinine ratio was $\geq 20 \mathrm{mg} / \mathrm{g}$ in men or $\geq 30 \mathrm{mg} / \mathrm{g}$ in women. High $3 \%$ ODI was defined as $\geq 30.2 / \mathrm{h}$, which was equivalent to the top $50 \%$ of the participants. OSA, obstructive sleep apnea; AHI, apnea-hypopnea index; 3\% ODI, oxygen desaturation ( $\geq 3 \%$ index

Table 5 Clinical effects of CPAP in patients with severe OSA ${ }^{a}$ and high serum periostin ${ }^{b}$

\begin{tabular}{|c|c|c|c|c|c|c|}
\hline \multirow[t]{2}{*}{ Index } & \multicolumn{3}{|c|}{ Severe OSA ${ }^{a}$ alone $(\boldsymbol{n}=35)$} & \multicolumn{3}{|c|}{ Severe + high periostin $^{b}(\boldsymbol{n}=8)$} \\
\hline & Baseline & $3 \mathrm{M}$ after CPAP & $\boldsymbol{p}$-value & Baseline & $3 \mathrm{M}$ after CPAP & $\boldsymbol{p}$-value \\
\hline $\mathrm{BMI}, \mathrm{kg} / \mathrm{m}^{2}$ & $28.7 \pm 4.8$ & $28.9 \pm 4.5$ & 0.47 & $28.2 \pm 3.5$ & $28.6 \pm 3.4$ & 0.18 \\
\hline $\mathrm{AHI}$, events/h & $52.3 \pm 18$ & $3.4 \pm 3.8$ & $<0.01$ & $51.3 \pm 15.9$ & $5.1 \pm 4.5$ & $<0.01$ \\
\hline $\mathrm{CT}_{90}, \%$ & $22.4 \pm 23.7$ & $0.2 \pm 0.8$ & $<0.01$ & $14 \pm 6$ & $0.7 \pm 1.3$ & 0.05 \\
\hline $3 \%$ ODI, events/h & $50.1 \pm 19.5$ & $2.8 \pm 3.6$ & $<0.01$ & $46.5 \pm 16$ & $4.5 \pm 4.3$ & $<0.01$ \\
\hline Arousal index, events/h & $50 \pm 17.7$ & $18.9 \pm 6.8$ & $<0.01$ & $43.7 \pm 14$ & $20.2 \pm 8.5$ & $<0.01$ \\
\hline Lowest oxygen saturation, \% & $75.5 \pm 7.8$ & $91.1 \pm 4.1$ & $<0.01$ & $72.9 \pm 8.5$ & $89.5 \pm 3.3$ & $<0.01$ \\
\hline Serum periostin, $\mathrm{ng} / \mathrm{mL}$ & $60.1 \pm 14$ & $61.8 \pm 15.5$ & 0.38 & $104.1 \pm 15.8$ & $94 \pm 10.8$ & 0.04 \\
\hline Total cholesterol, mg/dL & $199 \pm 39$ & $193 \pm 38$ & 0.21 & $201 \pm 27$ & $203 \pm 29$ & 0.58 \\
\hline High-density lipoprotein, mg/dL & $52 \pm 14$ & $52 \pm 12$ & 0.92 & $53 \pm 14$ & $56 \pm 15$ & 0.05 \\
\hline Low-density lipoprotein, mg/dL & $122 \pm 29$ & $119 \pm 31$ & 0.48 & $118 \pm 19$ & $123 \pm 19$ & 0.27 \\
\hline Triglycerides, mg/dL & $179 \pm 159$ & $153 \pm 95$ & 0.12 & $204 \pm 122$ & $207 \pm 95$ & 0.79 \\
\hline Free fatty acids, mg/dL & $464 \pm 145$ & $457 \pm 171$ & 0.81 & $609 \pm 106$ & $515 \pm 116$ & 0.25 \\
\hline Blood glucose, mg/dL & $99 \pm 23$ & $96 \pm 18$ & 0.64 & $120 \pm 37$ & $101 \pm 17$ & 0.66 \\
\hline Hemoglobin A1c, \% & $6.1 \pm 0.8$ & $6.0 \pm 0.7$ & 0.62 & $6.8 \pm 1.2$ & $6.2 \pm 0.6$ & 0.26 \\
\hline Albuminuriac, macro/micro/-, n & $1 / 3 / 31$ & $0 / 8 / 27$ & $0.16^{\mathrm{e}}$ & $1 / 3 / 4$ & $1 / 2 / 5$ & $0.32^{\mathrm{e}}$ \\
\hline Urinary albumin-creatinine ratio ${ }^{\mathrm{d}}, \mathrm{mg} / \mathrm{g}$ & $25.6 \pm 96.6$ & $12.7 \pm 34.2$ & $<0.01$ & $132.1 \pm 306.5$ & $60.6 \pm 121$ & $<0.01$ \\
\hline Average CPAP use, min/day & $304 \pm 78$ & & - & $385 \pm 70$ & & $0.01^{f}$ \\
\hline Percent days of CPAP use $>4 h, \%$ & $65 \pm 29$ & & - & $75 \pm 24$ & & $0.36^{f}$ \\
\hline
\end{tabular}

Data are presented as mean \pm SD or numbers

${ }^{a}$ Severe OSA was defined as OSA with $\mathrm{AHI} \geq 30$

${ }^{\mathrm{b}}$ Determined as high when the serum periostin level was $\geq 87 \mathrm{ng} / \mathrm{mL}$ (highest quintile) at baseline

'Defined as positive if the urinary albumin-creatinine ratio was $\geq 20 \mathrm{mg} / \mathrm{g}$ in men or $\geq 30 \mathrm{mg} / \mathrm{g}$ in women

dDefined as urine albumin/creatinine

eEvaluated by the McNemar test, which examined the changes in the frequency of albuminuria following CPAP treatment

${ }^{f}$ Comparison of the severe OSA with high periostin group with the severe OSA alone group

$C P A P$ continuous positive airway pressure, OSA obstructive sleep apnea, $B M I$ body mass index, $A H I$ apnea-hypopnea index; $C_{90}$, cumulative percentage of sleep time with percutaneous oxygen saturation $<90 \%$, ODI oxygen desaturation index 
the present study indicated that the presence of OSA in obese asthmatics should be suspected when the serum periostin level is elevated disproportionally to their BMI. Because OSA is a well-known comorbidity in obese patients with asthma [40] and contributes to poor asthma control $[4,41]$, serum periostin may assist in the management of this treatable trait in refractory asthma [42].

\section{Conclusions}

In conclusion, patients with severe OSA were clustered into two groups, severe OSA with and without comorbidities. In addition, high serum periostin in patients with OSA, despite being overweight/obese, may be an indicator of severe OSA with comorbidities, particularly albuminuria.

\section{Supplementary information}

Supplementary information accompanies this paper at https://doi.org/10. 1186/s12931-020-01413-0.

Additional file 1: Supplementary methods. Definitions of the severity of obstructive sleep apnea (OSA) and of high/low for the other sleep parameters. The definitions severity of OSA and high/low sleep parameters in the current study. Cluster analysis. The detailed description of cluster analysis. Definitions of comorbidities. The detailed definition of the presence of major comorbidities in the current study. Supplementary results. Characteristics of four clusters obtained according to cluster analysis. Cluster 1 was characterized mainly by younger age, male population, dyslipidemia, and high BMI but low prevalence of severe OSA. Among the four clusters, the patients in this cluster had the lowest serum periostin levels. Cluster 2 composed mainly of subjects with mild to moderate OSA and those with abnormal glycometabolism. Clusters 3 and 4 were characterized by the accumulation of severe OSA cases. Albuminuria was present in eight subjects in cluster 4 and in no subject in cluster 3. Of the eight subjects, six were positive for microalbuminuria (four with DM) and two exhibited macroalbuminuria (one with DM). Compared with cluster 3 , cluster 4 had higher mean \pm SD serum periostin level $(87.1 \mathrm{ng} / \mathrm{mL} \pm 32.3$ vs. $66.5 \pm 21.8 \mathrm{ng} / \mathrm{mL}, p=0.05)$; higher number of subjects with high serum periostin levels of $\geq 87 \mathrm{ng} / \mathrm{mL}$, which was the highest quintile of serum periostin $(p=0.02)$; and higher prevalence of asthma. Figure S1. Serum periostin levels in patients with/without comorbidities. The presence of major comorbidities was not associated with serum periostin levels. The black bars and the numbers in the figure represent the mean serum periostin level. Figure S2. Distribution of the four clusters on the axes of apnea-hypopnea index and serum periostin levels. The details of each cluster are described in Table 3 and in the supplementary results ("Characteristics of four clusters obtained according to cluster analysis"). The encircled size represents the number of subjects in each cluster. The encircled number represents the cluster number in Table 3. Figure S3. Serum periostin level in OSA. Overweight/obesity has negative impacts on the serum periostin level in OSA, as observed in the general population. However, high intermittent hypoxia contributes to high serum periostin level. Furthermore, severe OSA and comorbid albuminuria show positive interactions for serum periostin level. A high serum periostin in patients with OSA despite being overweight/obese may indicate a phenotype of OSA (i.e., severe OSA with albuminuria). Table S1. Clinical effects of CPAP in patients with moderate OSA. The serum periostin level did not decrease in subjects with moderate OSA after CPAP treatment $(p=0.75)$.

\section{Abbreviations}

AHI: Apnea-hypopnea index; Al: Arousal index; BMI: Body mass index; COPD: Chronic obstructive pulmonary disease; CPAP: Continuous positive airway pressure; $\mathrm{CT}_{90}$ : Cumulative percentage of sleep time with percutaneous oxygen saturation < 90\%; DM: Diabetes mellitus; $3 \%$ ODI: Oxygen desaturation ( $\geq 3 \%$ ) index; OSA: Obstructive sleep apnea;
PSG: Polysomnography; Th2: T helper type 2; UACR: Urine albumin-creatinine ratio

\section{Acknowledgments}

The authors thank Kazuyuki Ueda, Yuko Yamanishi, Akemi Ishii, Yuri Masuda, Yumiko Narita, and Rie Imai for analyzing the polysomnographic data.

\section{Authors' contributions}

H.S., H.M., R.T., S.O., K.I., T.H., and K.C. gave substantial contributions to the conceptualization and design of the study. R.T., T.M., K.T., T.O., and K.C. participated in data acquisition. H.S., H.M., R.T., J.O., and K.C. participated in the analysis of data. H.S., H.M., R.T., T.M., K.T., T.O., and K.C. interpreted the data. H.S. drafted the manuscript for important intellectual content. H.M., T.H., and K.C. critically revised the manuscript for important intellectual content. All authors gave final approval of the version to be published and accountability for all aspects of the work.

\section{Funding}

No funding was received for this study. However, the Departments of Respiratory Care and Sleep Control Medicine were funded by endowments from Philips-Respironics, Teijin Pharma, Fukuda Denshi, and Fukuda LifetecKeiji to Kyoto University.

\section{Availability of data and materials}

The datasets analyzed during the current study are not publicly available, because the consent obtained from the participants specified that the data can be used only for research purposes at our institution. The datasets can only be available from the corresponding author upon reasonable request and after the approval of the ethics committee of Kyoto University.

\section{Ethics approval and consent to participate}

This study was approved by the ethics committee of Kyoto University and was registered in the UMIN Clinical Trials Registry (Registry ID UMIN000012639). Written informed consent was obtained from all participants.

\section{Consent for publication}

Not applicable.

\section{Competing interests}

The authors declare that they have no competing interests.

\section{Author details}

${ }^{1}$ Department of Respiratory Medicine, Graduate School of Medicine, Kyoto University, 54 Kawaharacho, Shogoin, Sakyo-ku, Kyoto city, Kyoto prefecture 606-8507, Japan. ${ }^{2}$ Department of Respiratory Care and Sleep Control Medicine, Graduate School of Medicine, Kyoto University, 54 Kawaharacho, Shogoin, Sakyo-ku, Kyoto City, Kyoto prefecture 606-8507, Japan. ${ }^{3}$ Shino-Test Corporation, 2-29-4 Oonodai, Minami-ku, Sagamihara City, Kanagawa prefecture 252-0331, Japan. ${ }^{4}$ Department of Laboratory Medicine, Saga Medical School, 5-1-1 Nabeshima, Saga City, Saga prefecture 840-8502, Japan. ${ }^{5}$ Division of Biochemistry, Department of Biomolecular Science, Saga Medical School, 5-1-1 Nabeshima, Saga City, Saga prefecture 840-8502, Japan.

Received: 20 February 2020 Accepted: 3 June 2020

Published online: 09 June 2020

References

1. Peppard PE, Young T, Barnet JH, Palta M, Hagen EW, Hla KM. Increased prevalence of sleep-disordered breathing in adults. Am J Epidemiol. 2013; 177:1006-14.

2. Marin JM, Soriano JB, Carrizo SJ, Boldova A, Celli BR. Outcomes in patients with chronic obstructive pulmonary disease and obstructive sleep apnea: the overlap syndrome. Am J Respir Crit Care Med. 2010;182:325-31.

3. Malhotra A, Schwartz AR, Schneider H, Owens RL, DeYoung P, Han MLK, et al. Research priorities in pathophysiology for sleep-disordered breathing in patients with chronic obstructive pulmonary disease: an official American Thoracic Society research statement. Am J Respir Crit Care Med. 2018;197: 289-99. 
4. Teodorescu M, Polomis DA, Hall SV, Teodorescu MC, Gangnon RE, Peterson AG, et al. Association of obstructive sleep apnea risk with asthma control in adults. Chest. 2010;138:543-50.

5. Adedayo AM, Olafiranye O, Smith D, Hill A, Zizi F, Brown C, et al. Obstructive sleep apnea and dyslipidemia: evidence and underlying mechanism. Sleep Breath. 2014;18:13-8.

6. Abuyassin B, Sharma K, Ayas NT, Laher I. Obstructive sleep apnea and kidney disease : a potential bidirectional relationship? J Clin Sleep Med. 2015;11:915-24.

7. Ye L, Pien GW, Ratcliffe SJ, Björnsdottir E, Arnardottir ES, Pack Al, et al. The different clinical faces of obstructive sleep apnoea: a cluster analysis. Eur Respir J. 2014;44:1600-7.

8. Vavougios GD, Natsios G, Pastaka C, Zarogiannis SG, Gourgoulianis KI. Phenotypes of comorbidity in OSAS patients: combining categorical principal component analysis with cluster analysis. J Sleep Res. 2016;25:31-8.

9. Sánchez-De-La-Torre M, Khalyfa A, Sánchez-De-La-Torre A, Martinez-Alonso M, Martinez-García MÁ, Barceló A, et al. Precision medicine in patients with resistant hypertension and obstructive sleep apnea blood pressure response to continuous positive airway pressure treatment. J Am Coll Cardiol. 2015; 66:1023-32.

10. Kanemitsu Y, Matsumoto H, Izuhara K, Tohda Y, Kita H, Horiguchi T, et al. Increased periostin associates with greater airflow limitation in patients receiving inhaled corticosteroids. J Allergy Clin Immunol. 2013;132:305-12 e3.

11. Izuhara K, Conway SJ, Moore BB, Matsumoto H, Holweg CTJ, Matthews JG, et al. Roles of periostin in respiratory disorders. Am J Respir Crit Care Med. 2016;193:949-56.

12. Izuhara K, Nunomura S, Nanri Y, Ono J, Takai M, Kawaguchi A. Periostin: an emerging biomarker for allergic diseases. Allergy. 2019;74:2116-28.

13. Matsusaka M, Kabata H, Fukunaga K, Suzuki Y, Masaki K, Mochimaru T, et al. Phenotype of asthma related with high serum periostin levels. Allergol Int. 2015:64:175-80

14. Sunadome $H$, Matsumoto $H$, Petrova G, Kanemitsu Y, Tohda $Y$, Horiguchi T, et al. IL4Ra and ADAM33 as genetic markers in asthma exacerbations and type-2 inflammatory endotype. Clin Exp Allergy. 2017:47:998-1006.

15. Kimura H, Konno S, Makita H, Taniguchi N, Kimura H, Goudarzi H, et al. Serum periostin is associated with body mass index and allergic rhinitis in healthy and asthmatic subjects. Allergol Int. 2018;67:357-63.

16. Shirai T, Hirai K, Gon Y, Maruoka S, Mizumura K, Hikichi M, et al. Combined Assessment of Serum Periostin and YKL-40 May Identify Asthma-COPD Overlap. J Allergy Clin Immunol Pract. 2018;7:134-45 e1.

17. Rosselli-Murai LK, Almeida LO, Zagni C, Galindo-Moreno P, Padial-Molina M, Volk SL, et al. Periostin responds to mechanical stress and tension by activating the MTOR signaling pathway. PLoS One. 2013;8:e83580.

18. Zhang Z, Nie F, Kang C, Chen B, Qin Z, Ma J, et al. Increased periostin expression affects the proliferation, collagen synthesis, migration and invasion of keloid fibroblasts under hypoxic conditions. Int J Mol Med. 2014 34:253-61

19. Jordan AS, McSharry DG, Malhotra A. Adult obstructive sleep apnoea. Lancet. 2014;383:736-47.

20. Cameli P, Bergantini L, D’alessandro M, Vietri L, Refini RM, Pieroni M, et al. Alveolar nitric oxide is related to periostin levels in idiopathic pulmonary fibrosis. Minerva Med. 2019 Epub ahead of print. https://doi.org/10.23736/ S0026-4806.19.06321-3

21. Okamoto M, Izuhara K, Ohta S, Ono J, Hoshino T. Ability of Periostin as a new biomarker of idiopathic pulmonary fibrosis. Adv Exp Med Biol. 2019, 1132:79-87.

22. Nakazeki F, Nishiga M, Horie T, Nishi H, Nakashima Y, Baba O, et al. Loss of periostin ameliorates adipose tissue inflammation and fibrosis in vivo. Sci Rep. 2018;8:8553.

23. Lu $Y$, Liu $X$, Jiao $Y$, Xiong $X$, Wang $E$, Wang $X$, et al. Periostin promotes liver steatosis and hypertriglyceridemia through downregulation of PPARa. J Clin Invest. 2014;124:3501-13

24. Satirapoj B, Tassanasorn S, Charoenpitakchai M, Supasyndh O. Periostin as a tissue and urinary biomarker of renal injury in type 2 diabetes mellitus. PLoS One. 2015:10:e0124055

25. Tachikawa R, Ikeda K, Minami T, Matsumot T, Hamada S, Murase K, et al. Changes in energy metabolism after continuous positive airway pressure for obstructive sleep apnea. Am J Respir Cell Crit Care Med. 2016;194:729-38.

26. Berry RB, Budhiraja R, Gottlieb DJ, Gozal D, Iber C, Kapur VK, et al. Rules for scoring respiratory events in sleep: update of the 2007 AASM manual for the scoring of sleep and associated events. Deliberations of the sleep apnea definitions task force of the American Academy of sleep medicine. J Clin Sleep Med. 2012;8:597-619.

27. Matsumoto T, Murase $K$, Tachikawa R, Minami T, Hamada S, Tanizawa K, et al. Microalbuminuria in patients with obstructive sleep apnea-chronic obstructive pulmonary disease overlap syndrome. Ann Am Thorac Soc. 2016;13:917-25

28. de Jong PE. Screening, monitoring, and treatment of albuminuria: public health perspectives. J Am Soc Nephrol. 2006;17:2120-6.

29. Zinchuk AV, Gentry MJ, Concato J, Yaggi HK. Phenotypes in obstructive sleep apnea : a definition, examples and evolution of approaches. Sleep Med Rev. 2017;35:113-23.

30. Kent BD, Ryan S, McNicholas WT. Obstructive sleep apnea and inflammation: relationship to cardiovascular co-morbidity. Respir Physiol Neurobiol. 2011;178:475-81.

31. Takahashi K, Ueda S, Kobayashi T, Nishiyama A, Fujisawa Y, Sugaya T, et al. Chronic intermittent hypoxia-mediated renal sympathetic nerve activation in hypertension and cardiovascular disease. Sci Rep. 2018,8:17926.

32. Wu H, Li GN, Xie J, Li R, Chen QH, Chen JZ, et al. Resveratrol ameliorates myocardial fibrosis by inhibiting ROS/ERK/TGF- $\beta$ /periostin pathway in STZinduced diabetic mice. BMC Cardiovasc Disord. 2016;16:5.

33. Prakoura N, Kavvadas P, Dussaule J. NF k B-induced periostin activates integrin-b3 signaling to promote renal injury in gn. J Am Soc Nephrol. 2017 28:1475-90.

34. Koh SJ, Choi Y, Kim BG, Lee KL, Kim DW, Kim JH, et al. Matricellular protein periostin mediates intestinal inflammation through the activation of nuclear factor kb signaling. PLoS One. 2016;11:e0149652.

35. Mael-Ainin M, Abed A, Conway SJ, Dussaule J-C, Chatziantoniou C. Inhibition of periostin expression protects against the development of renal inflammation and fibrosis. J Am Soc Nephrol. 2014;25:1724-36.

36. Caswell-Smith R, Hosking A, Cripps T, Holweg C, Matthews J, Holliday M, et al. Reference ranges for serum periostin in a population without asthma or chronic obstructive pulmonary disease. Clin Exp Allergy. 2016:46:1303-14.

37. Faulx MD, Storfer-Isser A, Kirchner HL, Jenny NS, Tracy RP, Redline S. Obstructive sleep apnea is associated with increased urinary albumin excretion. Sleep. 2007;30:923-9.

38. Abuyassin B, Badran M, Ayas NT, Laher I. Intermittent hypoxia causes histological kidney damage and increases growth factor expression in a mouse model of obstructive sleep apnea. PLoS One. 2018;13:e0192084.

39. Izuhara K, Nunomura S, Nanri Y, Ogawa M, Ono J, Mitamura Y, et al. Periostin in inflammation and allergy. Cell Mol Life Sci. 2017;74:4293-303.

40. loachimescu OC, Teodorescu M. Integrating the overlap of obstructive lung disease and obstructive sleep apnoea: OLDOSA syndrome. Respirology. 2013:18:421-31.

41. ten Brinke A, Sterk PJ, Masclee AAM, Spinhoven P, Schmidt JT, Zwinderman $\mathrm{AH}$, et al. Risk factors of frequent exacerbations in difficult-to-treat asthma. Eur Respir J. 2005;26:812-8.

42. Davies SE, Bishopp A, Wharton S, Turner AM, Mansur AH. Does continuous positive airway pressure (CPAP) treatment of obstructive sleep apnoea (OSA) improve asthma-related clinical outcomes in patients with co-existing conditions?- a systematic review. Respir Med. 2018;143:18-30.

\section{Publisher's Note}

Springer Nature remains neutral with regard to jurisdictional claims in published maps and institutional affiliations.

Ready to submit your research? Choose BMC and benefit from:

- fast, convenient online submission

- thorough peer review by experienced researchers in your field

- rapid publication on acceptance

- support for research data, including large and complex data types

- gold Open Access which fosters wider collaboration and increased citations

- maximum visibility for your research: over $100 \mathrm{M}$ website views per year

At $\mathrm{BMC}$, research is always in progress.

Learn more biomedcentral.com/submissions 